\title{
Use of an oxygen planar optode to assess the effect of high velocity microsprays on oxygen penetration in a human dental biofilms in-vitro
}

Yalda Khosravi ${ }^{1}$, Rala D.P. Kandukuri², Sara R. Palmer ${ }^{3}$, Erin S. Gloag ${ }^{1}$, Sergey M. Borisov ${ }^{4}$, E. Michelle Starke ${ }^{5}$, Marilyn T. Ward ${ }^{5}$, Purnima Kumar ${ }^{3}$, Dirk de Beer ${ }^{2}$, Arjun Chennu ${ }^{2}$ and Paul Stoodley ${ }^{1,6,7^{*}}$ (D)

\begin{abstract}
Background: Dental plaque biofilms are the causative agents of caries, gingivitis and periodontitis. Both mechanical and chemical strategies are used in routine oral hygiene strategies to reduce plaque build-up. If allowed to mature biofilms can create anoxic microenvironments leading to communities which harbor pathogenic Gram-negative anaerobes. When subjected to high velocity fluid jets and sprays biofilms can be fluidized which disrupts the biofilm structure and allows the more efficient delivery of antimicrobial agents.

Methods: To investigate how such jets may disrupt anoxic niches in the biofilm, we used planar optodes to measure the dissolved oxygen (DO) concentration at the base of in-vitro biofilms grown from human saliva and dental plaque. These biofilms were subject to "shooting" treatments with a commercial high velocity microspray (HVM) device.

Results: HVM treatment resulted in removal of much of the biofilm and a concurrent rapid shift from anoxic to oxic conditions at the base of the surrounding biofilm. We also assessed the impact of HVM treatment on the microbial community by tracking 7 target species by qPCR. There was a general reduction in copy numbers of the universal $16 \mathrm{~S}$ RNA by approximately 95\%, and changes of individual species in the target region ranged from approximately 1 to 4 log reductions.
\end{abstract}

Conclusion: We concluded that high velocity microsprays removed a sufficient amount of biofilm to disrupt the anoxic region at the biofilm-surface interface.

Keywords: Mechanical disruption, Microspray, Oral, Biofilm, Planar optodes, Dissolved oxygen

\section{Background}

Oral microbial biofilms are complex communities of bacteria and fungi which grow on the teeth and soft tissues of the mouth. Dental/plaque biofilm formation progresses along an ecological succession starting with early

\footnotetext{
* Correspondence: paul.stoodley@osumc.edu

'Department of Microbial Infection and Immunity, Ohio State University, Columbus, USA

${ }^{6}$ Department Orthopaedics, Ohio State University, Columbus, USA Full list of author information is available at the end of the article
}

commensal colonizers such as facultative anaerobic oral streptococci [1-4].

In the early stages of plaque formation Streptococci, such as $S$. oralis and S. gordonii, attach, followed by a succession of organisms, which attach to the streptococci through a process known as coaggregation $[5,6]$. As these organisms metabolize dietary sugars they consume oxygen to lower the local dissolved oxygen (DO) concentration at the base of the biofilm, produce acids, and metabolites that may favor or antagonize other

(C) The Author(s). 2020, corrected publication 2020. Open Access This article is licensed under a Creative Commons Attribution 4.0 International License, which permits use, sharing, adaptation, distribution and reproduction in any medium or format, as long as you give appropriate credit to the original author(s) and the source, provide a link to the Creative Commons licence, and indicate if changes were made. The images or other third party material in this article are included in the article's Creative Commons licence, unless indicated otherwise in a credit line to the material. If material is not included in the article's Creative Commons licence and your intended use is not permitted by statutory regulation or exceeds the permitted use, you will need to obtain permission directly from the copyright holder. To view a copy of this licence, visit http://creativecommons.org/ licenses/by/4.0/. The Creative Commons Public Domain Dedication waiver (http://creativecommons.org/publicdomain/zero/1. 0/) applies to the data made available in this article, unless otherwise stated in a credit line to the data. 
community members. As the biofilm matures, anaerobic bacteria such as Veillonella parvula, Fusobacterium nucleatum and Porphyromonas gingivalis proliferate [7].

For those on a high- sugar diet acid fermentation by the cariogenic pathogen, S. mutans results in lowering the $\mathrm{pH}$ within the biofilm, as well as the production of an extracellular insoluble glucans which provides volume, structure and mechanical stability to the developing biofilm. As the thickness of the biofilm increases diffusion limitation of oxygen into the biofilm and metabolites out of the biofilm results in the build-up of steep gradients from physiological conditions to acidic and anoxic within $100 \mu \mathrm{m}$ [8]. The oral cavity and especially the periodontal pocket provides a unique ecosystem for microbial organisms and harbors a diverse microbiota with up to 700 prokaryote species [9]. One model for pathogenesis of periodontitis suggests that periodontal microbial communities can be clustered into complexes that are associated with disease severity [1012]. Seminal work, at that time based on culture dependent techniques, of Socransky identified a "red complex" harboring Porphyromonas gingivalis, Tannerella forsythia, and Treponema denticola, associated with the severe form of periodontitis. Further complexes included an intermediate orange complex with, e.g., Fusobacterium nucleatum and a yellow and green complex dominated by Streptococcus spp., the latter being associated with health. Support for a classical role for the red complex as direct pathogens came from the observation by Holt showing induction of periodontitis upon oral implantation of these bacteria in non-human primates [13]. However, more recent concepts suggest that keystone pathogens can disrupt tissue homeostasis and change the composition of the commensal microbiota thereby generating host immune modulation and dysbiosis, that is responsible for periodontitis $[14,15]$. Such a concept takes into account observations that periodontal pathogens often are low abundant and can be present in healthy people [16]. Periodontitis resembles the process of microbial succession with an increase of periodontitis-associated taxa while health-associated species remain but decrease in number. In turn, the microbial community structure changes significantly, and biomass typically increases [10].. P. gingivalis can also occur in the saliva and supragingival plaque both in healthy patients $(\approx 10 \%)$ and those with chronic periodontitis $(\approx 60 \%)$ [17], presumably protected in the microaerophilic or anoxic environment of attached biofilm or detached biofilm aggregates.

Dental biofilms, are recalcitrant to antimicrobial agents as well as to complete mechanical removal, when growing in places difficult to reach with tooth-brush bristles. High velocity microspray (HVM) is a new technology which provides an alternative to string flossing for interproximal plaque management, and has been shown in clinical trials to reduce plaque and gingival index when used in combination with manual and electric toothbrushes and mouthwashes [18-20]. However, the precise mechanism(s) of action are not known. In a recent in vitro study we reported that a commercial HVM device designed for interproximal cleaning removed significant amounts of a S. mutans biofilm, but intriguingly caused the small amount of remaining biofilm to flow, forming interfacial instabilities between the air/water spray and the biofilm [21]. This effect allowed much deeper penetration of particles and antimicrobial agents into the biofilm than could be achieved by shaking at $200 \mathrm{rpm}$ for $30 \mathrm{~s}$ alone [22]. We hypothesized that a combination of removal and mixing might disrupt the pathogenic anoxic environment at the base of the biofilm, thus potentially directing the biofilm community from pathogenic to commensal by modifying the environment, rather than purely trying to kill the biofilm bacteria with antimicrobial agents.

To test our hypotheses biofilms grown from saliva and toothbrush recovered plaque from healthy volunteers were grown on oxygen planar optodes [23, 24]. The oxygen concentration was measured prior to and after two daily shootings with a high velocity water spray. Reduction in the amount of total bacteria and 7 species representing early and late colonizers of various Socransky microbial complexes [10] was quantified by qPCR.

\section{Methods}

\section{Planar optode imaging system}

The planar optode imaging instrumentation was developed at the Max Planck Institute in Bremen, Germany. The setup comprised of a $45 \mathrm{~cm} \times 20 \mathrm{~cm} \times 20 \mathrm{~cm}$ illumination and imaging unit (Fig. 1). It housed a $8.8 \mathrm{MP}$ color camera (Flea3 USB from FLIR Systems Inc.), mounted on a linear stage to aid in focusing the field of view on to a sample opening at the top of housing. The camera was equipped with a $25 \mathrm{~mm}$ objective lens fitted with a $530 \mathrm{~nm}$ long-pass filter (Schott, North America). The top opening allowed samples to be imaged from below with controlled LED illumination $(455 \mathrm{~nm}$ with a cut-off filter at $470 \mathrm{~nm}$ ) which were positioned within the housing. Ambient light was eliminated by covering the opening with aluminum foil. The spatial resolution in the focal plane was $25 \mu \mathrm{m} /$ pixel.

\section{Optode manufacture}

The optode foils were prepared according to Larsen et al. [25]. However, a lipophilic coumarin dye $\mathrm{Bu}_{3}$ Coum [26] was used instead of Macrolex yellow in order to avoid leaching of the antenna dye out of the polymer. The sensor material contained $\mathrm{Bu}_{3}$ Coum (1.5\% wt.), an oxygen indicator Pt (II) porphyrin $(0.75 \%$ wt., Frontier 

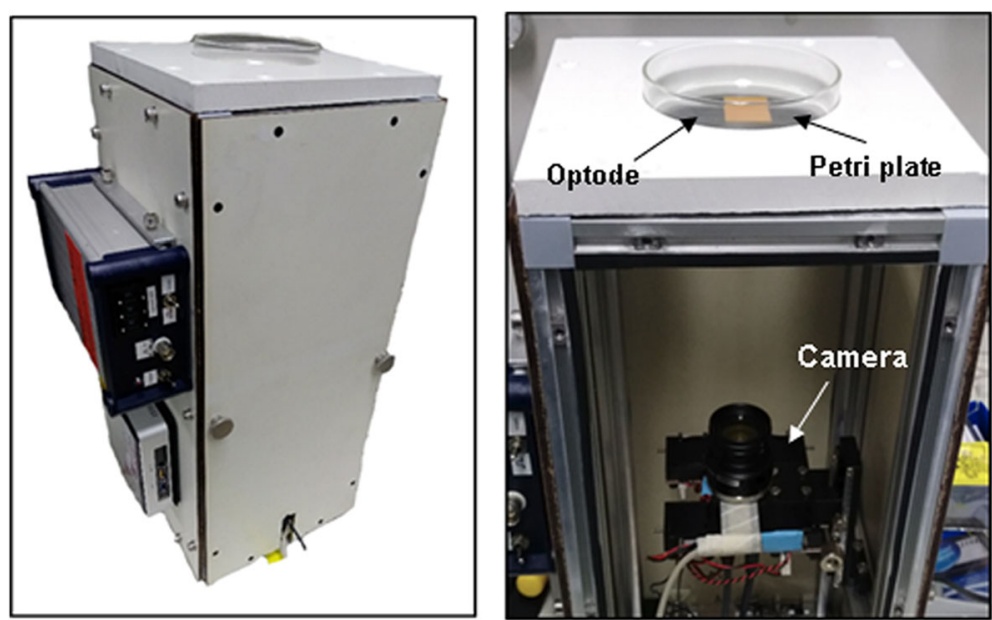

Fig. 1 Optode imaging system. The imaging system consisted of a camera fitted with a $25 \mathrm{~mm}$ objective and mounted on a movable stage to adjust focus on to the opening at the top. The biofilm growth chambers were placed on the circular opening at the top and covered to eliminate ambient light during imaging. Strobe lights ( $455 \mathrm{~nm}$ LEDs) for fluorescence excitation were installed beside the imager. The left panel shows the system enclosed in a case to eliminate ambient light and the right panel shows the configuration of the system components and the sample

Scientific, frontiersci.com) embedded in polystyrene (MW 250000) along with $50 \%$ by wt. of $\mathrm{TiO}_{2}$ nanoparticles (P170, Kemira, Finland). This mixture was dissolved in chloroform ( $4.5 \mathrm{~g}$ per $300 \mathrm{mg}$ polystyrene) (Sigma, USA) and coated in a $2 \mu \mathrm{m}$ thick layer on a clear polyethylene terephthalate sheet (Melinex 505, Pütz, Germany). The optodes were then stored dry and in the dark until used for the sample measurement setup.

\section{Calibration of the optodes}

The ratio of the red and green channels in the color images of the optode can be calibrated for dissolved oxygen (DO) using a modified Stern-Volmer equation [25, 27]. The response is not linear but follows an exponential decay and thus a multi-point calibration is required to characterize the nature of the decay on a subset of the optodes. To achieve this, the signal of a de-aerated $\mathrm{N}_{2}$ sparged solution is measured simultaneously with a DO concentration from a microelectode system (Unisense) as the solution is sparged by bubbling with air and thus becomes re-oxygenated. Once the general response was characterized we used the SternVolmer equation to fit intermediate points between the 2 measured points; zero and $100 \%$ saturation on the other optodes. The $0 \% \mathrm{DO}$ solution was made by adding $3 \mathrm{~g}$ of ascorbic acid $\left(\mathrm{C}_{6} \mathrm{H}_{8} \mathrm{O}_{6}, 99.9 \%\right)$, (Sigma, USA) in $50 \mathrm{~mL}$ of tap water and adjusting $\mathrm{pH}$ to 11 with $\mathrm{NaOH}$. A $100 \%$ DO solution was obtained by bubbling demineralized water with air for $10 \mathrm{~min}$. Since the biofilms were to be grown in a modified brain heart infusion (M-BHI) broth, we used a conversion to account for the lower solubility of DO in BHI [28]. Calibration and measurements were performed at $22^{\circ} \mathrm{C}$ Such optodes have been designed to be insensitive to $\mathrm{pH}$, salinity and $\mathrm{CO}_{2}$ [27].

\section{Sterilization of optodes}

After calibration, the optodes were sanitized in generic mouthwash containing $1.5 \% \mathrm{H}_{2} \mathrm{O}_{2}, 0.07 \%$ cetylpyridinium chloride for $30 \mathrm{~min}$ at room temperature. The optodes were then rinsed with $\mathrm{dH}_{2} \mathrm{O}$, before being applied to the growth systems. We placed the optode in a petri dish with BHI (Sigma Aldrich, USA) and incubated it for $24 \mathrm{~h}$ at $37^{\circ} \mathrm{C}$ to confirm sterility by inspection for turbidity and plating the media on BHI (Sigma Aldrich, USA) agar. If there was no turbidity and no colonies observed, we proceeded with the experiment.

\section{Collection of human saliva / plaque inoculum}

This study was approved by the Ohio State University for Human Subject Research (Study Number: 2017H0016). Samples were collected from six consenting healthy adult donors, who did not self-report any known underlying chronic disease and were in good oral health using a protocol adapted from Nance et al. [29]. The donors had not received antibiotics for at least 3 months prior to collection. Collection of samples was performed in the morning for all volunteers. Volunteers were asked to refrain from eating after dinner the evening prior to and the morning of the collection. No oral hygiene was practiced for a minimum of $8 \mathrm{~h}$ prior to donating. To generate a saliva/plaque inoculum, $10 \mathrm{ml}$ of stimulated saliva was collected in a sterile plastic $50 \mathrm{~mL}$ tube (Falcon, Thermo Fisher Scientific, Waltham, MA, USA). Plaque was recovered using a standard toothbrush from the teeth and tongue by brushing but using no toothpaste. The toothbrush was vortexed in $10 \mathrm{~mL}$ PBS for 3 min (VortexGenie $^{\circ} 2$ mixer, Scientific Industries, Inc., Bohemia, N.Y., USA) to transfer the plaque from the brush to the PBS. 
Vortexing was conducted in an anaerobe chamber (Bactron, USA, with a $5 \% \mathrm{CO}_{2}, 5 \% \mathrm{H}_{2}$ and $90 \% \mathrm{~N}_{2}$ headspace) to avoid overexposure of $\mathrm{O}_{2}$ sensitive anaerobes during the mixing. The bacteria was pelleted by centrifugation $(10,000 \mathrm{~g}$ for $3 \mathrm{~min})$ and resuspended in the pooled saliva. Saliva and plaque were kept on wet ice through the whole collection procedure. Glycerol was added to a final concentration of $25 \%$. Aliquots of this suspension were stored in $1.5 \mathrm{~mL}$ cryogenic tubes (Thermo Fisher Scientific, USA) at $-80^{\circ} \mathrm{C}$.

\section{Growth media}

A modified brain heart infusion (M-BHI) broth was used for cultivations. BHI broth (Sigma Aldrich, USA) was supplemented with $5 \mathrm{mg} / \mathrm{L}$ hemin (Alpha Aesar, USA), $1 \mathrm{mg} / \mathrm{L}$ menadione (MP Biomedicals, LLC, France), 0.1 g/L L-cysteine (Sigma, USA) and $1 \mathrm{~g} / \mathrm{L}$ yeast extract (Sigma, USA). The growth media of current study was absent in. We were particularly interested to see if Gram negative strict anaerobes could survive and proliferate in a biofilm grown under an oxic headspace and we were concerned that adding sucrose would cause $S$. mutans and other acidogenic bacteruia to dominate since $P$. gingivalis is not acid tolerant [30].

\section{Biofilm growth systems}

Three growth systems were used. First we used hydroxyapatite (HA) discs to determine the time sequence for the development of the bacterial community under our growth conditions. For the optode work, we used a modified dual chamber slide (Nunc Lab-Tek, USA) and a polystyrene Petri dish (Corning $^{\mathrm{Tm}}$ Falcon, Thermo Fisher Scientific), both fitted with optode foils.

\section{Incubation conditions}

All biofilms were grown in a $5 \% \mathrm{CO}_{2}$ incubator at $37^{\circ} \mathrm{C}$ (Thermo Fisher Scientific). Conventionally, human plaque biofilms grown in vitro are done under anoxic conditions in an anaerobic chamber with as a low Eh (Redox potential) in the bulk fluid is required for the strict anaerobes [31]. However, we used an oxic headspace under the rationale that 1 ) the oral cavity is not anoxic and that the natural creation of anoxic microniches by the biofilm was more relevant and 2) to observe differences in DO at the base of the biofilm when disrupted by the microspray required an overlying oxic headspace, recapitulating the in vivo condition.

\section{Hydroxyapatite (HA) discs}

One $\mathrm{cm}$ diameter hydroxyapatite discs (BioSurface Technologies, Bozeman, MT) were placed into each well of a 12 well plate (Falcon, corning, USA) (Fig. 2a). Then $2 \mathrm{~mL}$ of sterile of M-BHI was added to each well followed by $500 \mu \mathrm{L}$ of the saliva/plaque inoculum. The

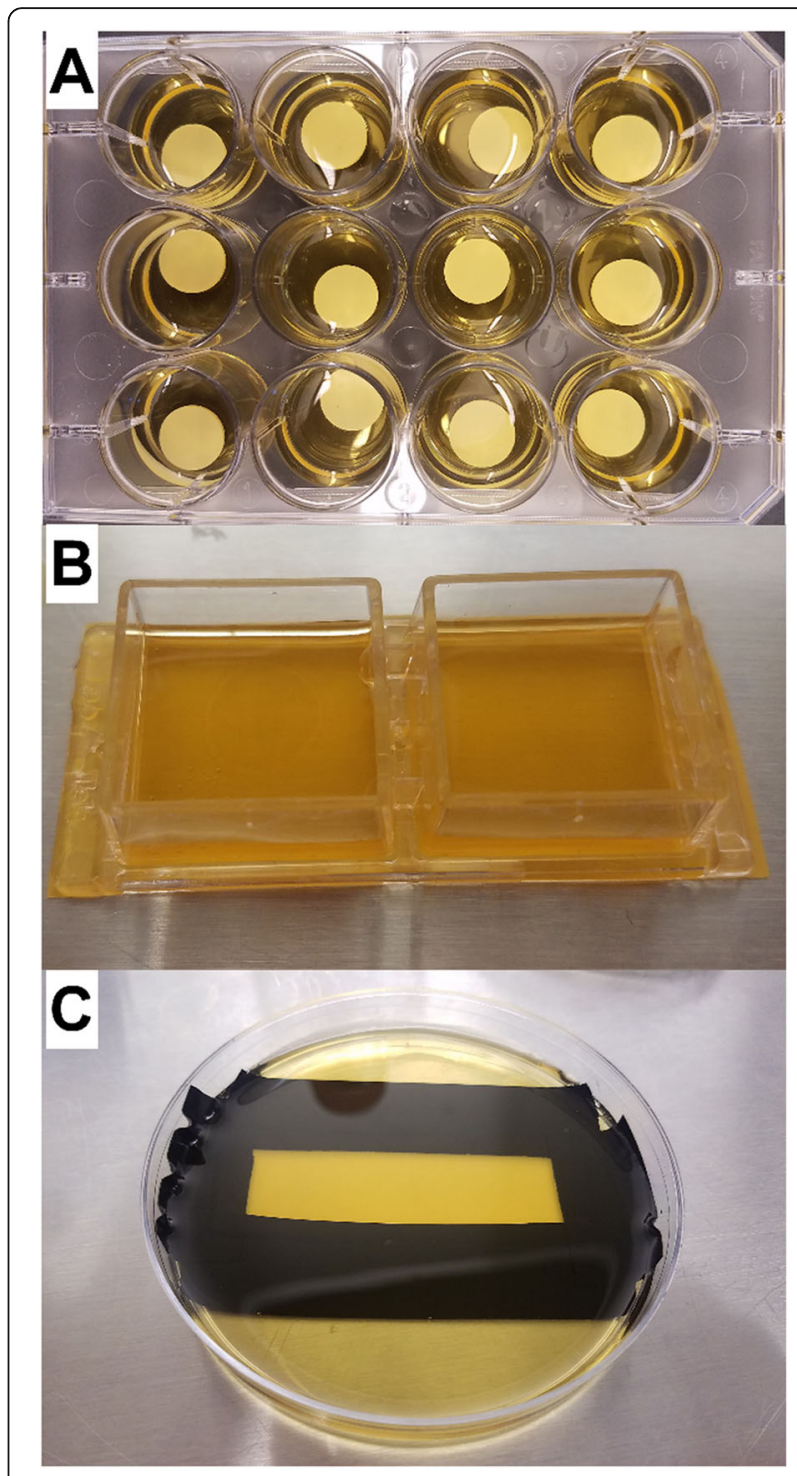

Fig. 2 Growth systems for saliva/plaque biofilms. a HA discs placed in wells of a 12 well plate with $2 \mathrm{~mL}$ of medium. $\mathbf{b}$ Dual chamber growth system. To make the chamber the glass microscope slide was replaced with a planar optode (yellowish amber) which was glued to the chambers with silicone. Two $\mathrm{mL}$ of medium was held in each well. c Petri plate growth system. The optode was fixed to the bottom of the Petri plate using electrical tape to prevent the seepage of medium underneath the optode. The optode was submerged under $5 \mathrm{~mL}$ of growth medium

biofilm was grown for 4 days with daily media exchanges. At each day a triplicate set of dics were sacrificed to yield DNA for 16S RNA gene phylogenetic analysis (see below for details) by transferring them to $50 \mathrm{~mL}$ tubes (Falcon, Thermo Fisher Scientific, USA) with $5 \mathrm{~mL}$ of sterile phosphate-buffered saline (PBS, Gibco, Thermo Fisher Scientific). Biofilm was removed by sonicating in a sonicator bath (Model \# 97043-964, VWR International, West Chester, PA, USA) for 3 min. 
The supernatant was then centrifuged (Legend micro 21, Thermo Fisher Scientific, USA) at 10,000 g for $10 \mathrm{~min}$. The supernatant was discarded, and the pellet used for DNA extraction.

\section{Dual chamber system}

In order to confine the biofilm to a defined area for the shooting experiment, a 2-well chamber slide with removable wells was used (Nunc ${ }^{\mathrm{TM}}$ Lab-Tek $^{\mathrm{Tm}}$ II Chamber Slide $^{\text {tw }}$ System, Thermo Fisher Scientific) (Fig. 2b). Each chamber was $2 \times 2 \mathrm{~cm}$ with a volume of $2 \mathrm{~mL}$. The cover slip that formed the base of the chamber was removed and an optode foil $22 \mathrm{~mm} \times 44 \mathrm{~mm}$ was glued in its place using silicon sealer. One chamber was used as an "untreated" control and the other as the experimental HVM treated chamber. The microspray shooting was performed in a laminar flow cupboard to contain possible aerosols. However, the microspray was so forceful in the small chamber that it displaced almost all of the reservoir liquid making the system messy and difficult to work with. Therefore, we also used a larger Petri plate system. The DO measurements were limited due to resources and we were only able to use one run for the dual chamber and Petri plate systems each.

\section{Petri plate system}

To overcome the problem of losing the water phase during HVM treatment, we used a $9 \mathrm{~cm}$ dia. Petri dish (Corning $^{\text {m }}$ Falcon, Thermo Fisher Scientific) to grow biofilms. A piece of optode film $22 \mathrm{~mm} \times 44 \mathrm{~mm}$ was fixed to the bottom of the plate with electrical tape. To prevent the seepage of medium underneath the optode and to prevent the formation of bubbles between the optode and the bottom of the plate, it was important to tightly seal all four sides of the optode (Fig. 2c). Electrical tape worked well because of its pliability. Another advantage of using this larger container was that the impinging spray was allowed to spread radically rather than splashing back out of the chamber system. In addition, the larger area of the optode meant that the area of biofilm dislodged by the treated area could be clearly delineated from the surrounding undisturbed areas, thus allowing oxygen mapping over both areas. A further advantage was that the optode was supported by the underlying plate and so the optode remained better positioned during HVM treatment.

\section{Biofilm growth in the dual chamber and petri plate optode systems}

The dual chamber and the Petri plate biofilms were grown under similar conditions with daily media exchanges and a daily inoculation from the pooled stock for a duration of 7 days. For the dual chamber system, 2 $\mathrm{mL}$ of sterile medium was added to each chamber and
$200 \mu \mathrm{L}$ of the stock inoculum was added to each well. For the Petri plate system, $5 \mathrm{~mL}$ of media was added and $500 \mu \mathrm{L}$ of inoculum. After days 1, 2, 3, 4, 6 and 7, the DO was mapped using the optode system by transferring the growth chamber (either dual chamber or Petri plate) to the optode imager and imaged immediately after exchanging the media, to assure the media to be fully oxic. On days 6 and 7, the biofilm was exposed "shot" with a commercial HVM device using a single pulse (AirFloss, Philips Oral Healthcare). The device was filled with tap water to generate a water microspray which lasted approximately $60 \mathrm{~ms}$ and dispensed approximately $130 \mu \mathrm{l}$ [21]. The HVM device was convenient for these studies since it could generate high velocity fluid flow while minimizing the volume of generated liquid waste [32, 33]. In the dual chamber system, one of the chambers was HVM treated while the other chamber was left as an untreated control. The tip of the HVM device was held approximately $1 \mathrm{~cm}$ from the surface of the optode during the microspray. DO images were taken before and after the treatment. After the final optode measurement on day 7, the biofilm growing on the optode in the Petri plate was removed for DNA extraction for identification of species and genera by PCR. A circular area of approximately $1 \mathrm{~cm}$ diameter in the HVM shot area was sampled by scraping with a sterile loop (Fisherbrand, disposable loop, Thermo Fisher Scientific). A similar area in the adjacent but undisturbed area was sampled in a similar manner to serve as an untreated control.

\section{Biofilm community analysis}

To ensure the bacterial community in the saliva/plaque inoculum included representative species (Table 1), we used conventional agarose gel PCR and assessed their relative abundance semi-quantitatively by gel densitometry. For biofilms grown on the HA discs and on the planar optodes in the HVM treated areas and the undisturbed biofilms, we used quantitative PCR (qPCR) to determine the presence and relative abundance of the target species.

\section{DNA extraction}

DNA from the saliva/plaque inoculum was extracted using a boiling method, which is a simple and cheap method that has been shown to be effective for human dental plaque, although for quantification is less sensitive than qPCR. In this method the scraped biofilm was boiled in double-distilled water (ddH2O) for $10 \mathrm{~min}$. and then chilled for $2 \mathrm{~min}$ at $20^{\circ} \mathrm{C}$. The sample was then centrifuged (Legend micro 21, Thermo Fischer Scientific, USA) at $16,000 \mathrm{~g}$ for $10 \mathrm{~min}$ at room temperature. Purity of the extracted DNA was based on the $260 / 280 \mathrm{~nm}$ optical density (OD) ratio by spectrophotometry (NanoDrop 1000, Thermo Fisher Scientific). For qPCR, DNA 
Table 1 Oligonucleotide PCR primer sets used to identify target species and genera in the biofilm by densiometric gel electrophoresis and $\mathrm{qPCR}$. For S. mutans the gtfB gene encoding glucosyltransferase was used. The other primers were for various regions of the $16 \mathrm{~S}$ rRNA gene

\begin{tabular}{|c|c|c|c|}
\hline Sequence of primer $\left(5^{\prime}-3^{\prime}\right)$ & Target and abbreviation & Product size & Reference \\
\hline $\begin{array}{l}\text { F, GTTGACAGCCGATGAAGAAGATGAA } \\
\text { R, TTCTCAGCAAAAGTACCGTCCTCG }\end{array}$ & S. oralis (So) & $81 \mathrm{bp}$ & [34] \\
\hline $\begin{array}{l}\text { F, GCCTACAGCTCAGAGATGCTATTCT } \\
\text { R, GCCATACACCACTCATGAATTGA }\end{array}$ & S. mutans (Sm) & $114 b p$ & [35] \\
\hline $\begin{array}{l}\text { F, GGTGTTGTTTGACCCGTTCAG } \\
\text { R, AGTCCATCCCACGAGCACAG }\end{array}$ & S. gordonii (Sg) & $96 \mathrm{bp}$ & [35] \\
\hline F,ATGTGGGTCTGACCTGCTGC ${ }^{c}$ & A. viscosus $(\mathrm{Av})^{c}$ & $96 \mathrm{bp}$ & [35] \\
\hline $\begin{array}{l}\text { F, GGATAGATGAAAGGTGGCCTCT } \\
\text { R, CCAACTAGCTAATCAGACGCAAT }\end{array}$ & V. parvula $(V p)^{a}$ & $72 \mathrm{bp}$ & [36] \\
\hline $\begin{array}{l}\text { F, CCGTGATGGGATGGAAACTGC } C^{b} \\
\text { R, CCTTCGCCACTGGTGTTCTTC }\end{array}$ & Veillonella. spp. (Vspp) ${ }^{b}$ & $102 \mathrm{bp}$ & [37] \\
\hline $\begin{array}{l}\text { F, CGCAGAAGGTGAAAGTCCTGTAT } \\
\text { R, TGGTCCTCACTGATTCACACAGA }\end{array}$ & $\begin{array}{l}\text { Fusobacterium.spp. } \\
\text { (Fspp) }\end{array}$ & $101 \mathrm{bp}$ & [35] \\
\hline $\begin{array}{l}\text { F, TAC CCATCGTCG CCTTGGT } \\
\text { R, CGGACTAAAACCGCATACACTTG }\end{array}$ & P. gingivalis $(\mathrm{Pg})$ & $126 \mathrm{bp}$ & [35] \\
\hline $\begin{array}{l}\text { F, CGCTAGTAATCGTGGATCAGAATG } \\
\text { R, TGTGACGGGCGGTGTGTA }\end{array}$ & Eubacteria (Uni) & $69 \mathrm{bp}$ & [35] \\
\hline
\end{tabular}

ased in conventional PCR

bused in qPCR

'due to uncertainty of taxonomic identification of $A$. viscosus with respect to identification of this species in human strains we denote this species in quotation marks following Könönen et al. [38]

was extracted immediately after the shot. For qPCR, we used the established method used in the "Human Oral Microbiome Identification using Next Generation Sequencing" (HOMINGS) protocols developed at the Forsyth Institute, for which we used an Epicenter, Puremaster Kit (Epicenter, Madison, WI) to extract DNA from biofilm [39].

\section{Conventional PCR and densitometry for the saliva/plaque inoculum}

PCR conditions (annealing temperature and numbers of PCR cycles) were optimized to identify 5 of the 7 target species and genera using the primer sets shown in Table 1. Amplification was performed in a $25 \mu \mathrm{l}$ mixture containing $\mathrm{Mg}^{2+}$, dNTPs, and recombinant Taq DNA Polymerase for routine PCR of fragments up to $5 \mathrm{~kb}$ (Invitrogen, USA), $10 \mu \mathrm{M}$ forward and reverse primers and $2 \mu \mathrm{l}$ bacterial DNA extract in a thermal cycler (MyCycler ${ }^{\mathrm{Tm}}$ Thermal Cycler system, BioRad). PCR was carried out using the following conditions: an initial denaturation step for $4 \mathrm{~min}$ at $94^{\circ} \mathrm{C}$, with 45 cycles of $30 \mathrm{~s}$ at $95^{\circ} \mathrm{C}, 1 \mathrm{~min}$ at $58^{\circ} \mathrm{C}$ and $30 \mathrm{~s}$ at $72^{\circ} \mathrm{C}$, followed by 5 min at $72{ }^{\circ} \mathrm{C}$. Agarose gel (Sigma, USA) was prepared at a concentration of $1.5 \%(\mathrm{w} / \mathrm{v})$ in $60 \mathrm{ml}$ Tris-Borate Buffer (TBE). One $\mu \mathrm{l}$ of $10 \mu \mathrm{g} / \mathrm{ml}$ ethidium bromide (Sigma, USA) was incorporated into the gel to make a final concentration of $0.5 \mu \mathrm{g} / \mathrm{ml}$ and electrophoresed at $90 \mathrm{~V}$ for $60 \mathrm{~min}$. The DNA bands were visualized using a gel documentation system (ChemiDoc XRS, Bio-Rad, USA) under ultraviolet (UV) illumination.

\section{qPCR for analysis of HA and optode grown biofilms}

qPCR was performed using an iQ5 real time PCR detection system (CFX96, Bio-Rad, USA). Each PCR was performed in a total volume of $20 \mu \mathrm{L}$ containing $2 \mu \mathrm{l}$ of $10 \times$ iQ SYBR ${ }^{\circ}$ Green Supermix (Bio-Rad, Hercules, CA), $0.5 \mu \mathrm{mol} / \mathrm{L}$ each of forward and reverse primers, $7 \mu \mathrm{l}$ of $\mathrm{ddH} 2 \mathrm{O}$ water, and $1 \mu \mathrm{l}(10 \mathrm{ng})$ of template DNA., depending on the ratio of the individual bacterial species within the biofilm. We used SYBR green rather than a TaqMan probe to make the assay more economical after Yamashita and Carrouel et al. [40, 41], however, we note limitations to this method, it is less specific and sensitive. Therefore, when using this method it is necessary to carefully check the primer concentration, buffer composition and denaturation and annealing times to verify a robust $\mathrm{qPCR}$ reaction. The $\mathrm{qPCR}$ was carried out with an initial incubation of $2 \mathrm{~min}$ at $95^{\circ} \mathrm{C}$, followed by $45 \mathrm{cy}$ cles of denaturation for $15 \mathrm{~s}$ at $95^{\circ} \mathrm{C}$, annealing for $1 \mathrm{~min}$ at $60^{\circ} \mathrm{C}$, melting curve $65^{\circ} \mathrm{C}$ to $95^{\circ} \mathrm{C}$ incremented by $0.5^{\circ} \mathrm{C}$ every $0.05 \mathrm{~s}$. Standard curves were generated for all the target bacteria using DNA from pure cultures and species specific DNA primers. Ten-fold serial dilutions of genomic DNA (DNA from $10^{7}$ to $10^{1}$ cells), from pure bacterial cultures provided seven data points for standard curve generation. In each standard curve, the concentration of standard sample (known amount of 
DNA/DNA from known number of bacteria) was plotted against its crossing points. Quantification of the individual target bacteria and total bacteria from the experimental samples were calculated using the standard curves. For each species, a standard curve was generated using defined concentrations of genomic input DNA (10-fold serial dilution). The genomic DNA amount of the target species or genera in the unknown sample was calculated from the standard curve. For the HA grown biofilms triplicate discs (biological replicates) were sacrificed for qPCR analysis on each of the 4 days. For the optode experiments biofilms were grown for 6 days with daily nutrient exchanges and then shot with the HVM on days 6 and 7. Triplicate unshot optodes were used for comparative controls. Three biological replicates containing three technical replicates were used in this set up experiment. Data were analyzed using Bio-Rad CFX manager software 3.1. qPCR analysis resulted in $\mathrm{Ct}$-values which were converted to copy number using a calibration curve and graphics were made using GraphPad Prism 8.0 (GraphPad Software, Inc., San Diego, CA). The student $\mathrm{t}$-test was used for qPCR data analysis. $P<$ 0.05 was considered significantly different.

\section{Confocal laser scanning microscope (CLSM)}

CLSM was used to measure the thickness and visualize the structure of the biofilm on the HA discs and the optodes in the undisturbed areas and the HVM "shot" areas. The dental/plaque biofilm was grown for 7 days on both surfaces, and shot on day 6 and 7. Briefly, on day 7 biofilms on the HA discs and optodes were rinsed two times with sterile saline to remove loose bacteria, and then "shot" with a HMV. Immediately after the shot, the samples rinsed with sterile water and the remaining bacteria were stained with $2.5 \mu \mathrm{M}$ SYTO 9 green fluorescent nucleic acid stain $(480 / 500 \mathrm{~nm}$; ThermoFisher Scientific) with a 30 min incubation in the dark at room temperature [42]. After incubation imaging was performed using an Olympus FV1000-MPE upright confocal/multiphoton microscope (Olympus Corp., USA) equipped with a $\times 25,1.05$-numerical-aperture water immersion dipping objective lens. The excitation wavelength was $488 \mathrm{~nm}$, and the emission wavelength filter for SYTO 9 was a 500/530 OlyMPFC1 filter. Each biofilm was scanned at three randomly selected positions in the HVM and undisturbed areas on three biological replicates of HA discs and one optode. The XY- $Z$ series were generated by optical sectioning at each of these positions. Graphics were made using GraphPad Prism 8.0 (GraphPad Software, Inc., San Diego, CA). COMSTAT2 [43] was used to measure the maximum thickness of the biofilm and student $t$-test run for data analysis. $P<0.05$ was considered significantly different.

\section{Results}

\section{Presence of the target species in the inoculum}

The pooled saliva/plaque inoculum was positive for all the targeted species and genera representing both aerobic and anaerobic species (Supplemental Fig. 1).

\section{Biofilms grown on the HA discs}

Macroscopically the biofilm grown on the optodes and the HA were heterogeneous and consisted of distinct microcolonies of up to $2 \mathrm{~mm}$ in diameter surrounded by a more uniform cream colored base film (Fig. 3). The biofilms were approximately $1 \mathrm{~mm}$ thick after 4 days. Over the course of 4 days of growth, there was a general increase in the biomass as demonstrated by the increase in copy number; however, individual species showed different trends (Fig. 4). After 1 day of growth, Veillonella spp. Fusobacteria spp. and S. oralis were the most dominant of the target species in the biofilm. There was small but steady decrease of the two streptococci over the 4 days while there was a general increase in the anaerobic species between days 1 and 3. At day 4, "A. viscosus", Veillonella spp., Fusobacterium spp. and P. gingivalis showed a subsequent decrease of approximately 10 to $20 \%$. In contrast there was an approximate 4 log increase in Fusobacteria spp. from days 3 to 4.

\section{Biofilms grown on the optodes}

The biofilm grown on the optode foils were similar in appearance to those grown on the HA discs and consisted of

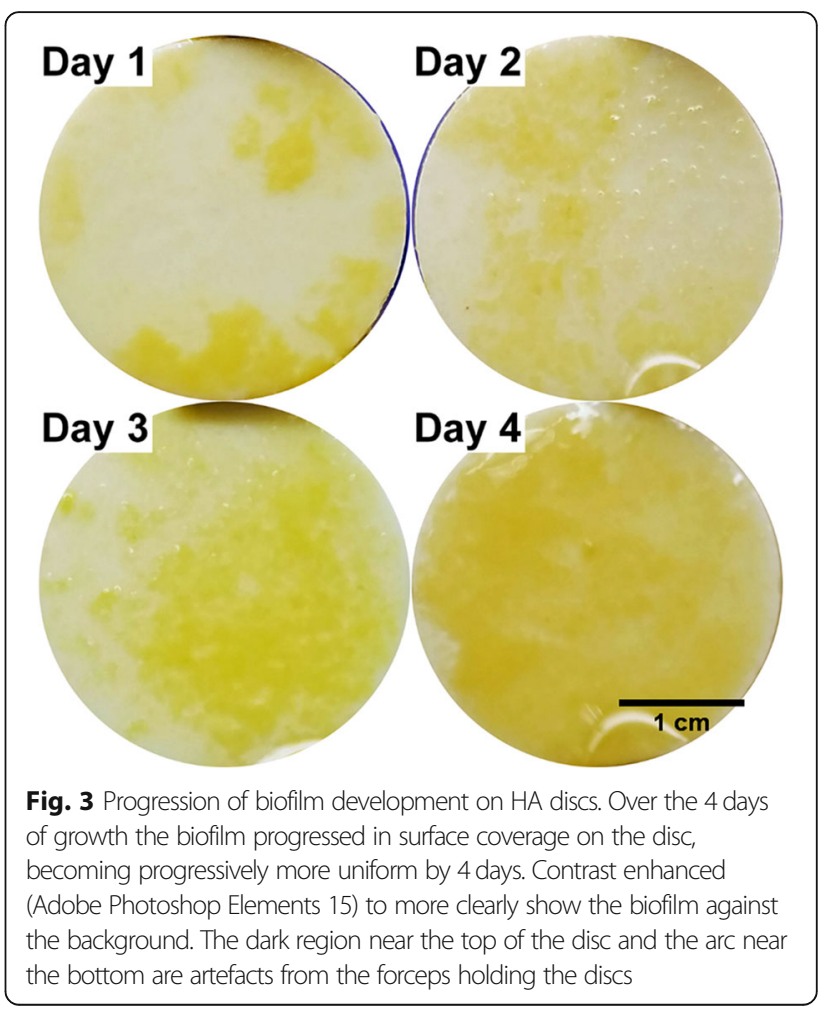




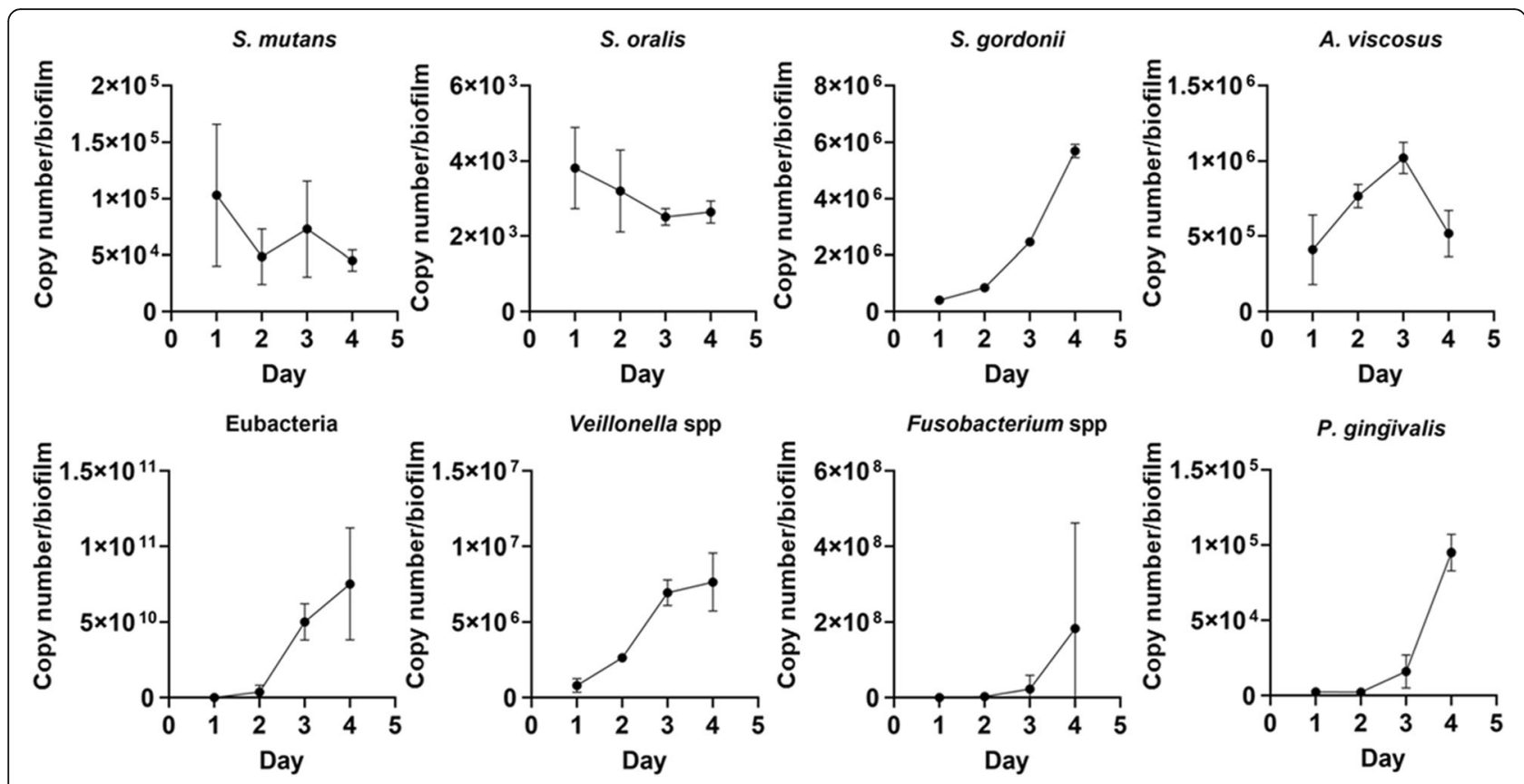

Fig. 4 Development of the biofilm community on the HA discs by qPCR. In the day 1 biofilm Veillonella spp. Fusobacteria spp. and S. oralis were the most dominant of the target species. There was a general trending increase in all of the anaerobic species between days 1 and 3. Data were mean and $1 \mathrm{SD}$

discrete microcolonies surrounded by a base film (Figs. 3 and 5). The larger microcolonies were approximately 1 to $2 \mathrm{~mm}$ diameter. After the biofilm was exposed to the HVM in the dual chamber system there was visible clearance of biofilm from the base of the chamber (Fig. 5). However, the HVM appeared to have forced biofilm to the chamber wall edges where it had accumulated (Fig. 6). In contrast the HVM treatment to the biofilm grown on the planar optode in the Petri plate created a well-defined circle of clearance, approximately $1 \mathrm{~cm}$ diameter, Epifluorescence microscopy showed that the larger aggregates had been removed from this area (Fig. 7).

\section{Thickness of biofilm}

Confocal microscopy imaging and the surface plot in the HVM treated areas showed that biofilms on both the HA and optode surfaces were highly heterogeneous (Fig. 5). Such heterogeneity might explain different oxygen concentrations at the base of the biofilm. The average maximum (in a field of view) thickness of biofilms on the HA discs was $55 \mu \mathrm{m}$ with a maximum thickness of $110 \mu \mathrm{m}$. Exposure to the HVM reduced the average maximum thickness to $15 \mu \mathrm{m}$ with the maximum measured value of $31 \mu \mathrm{m}$. For the optodes the average maximum in the undisturbed region was $75 \mu \mathrm{m}$ with a maximum thickness of $150 \mu \mathrm{m}$. Exposure to the HVM reduced the average maximum thickness to $8 \mu \mathrm{m}$ with the maximum measured value of $16 \mu \mathrm{m}$. These reductions were statistically significant $(P<0.05)$.

\section{Dual chamber system}

In the dual chamber the optode substratum was almost fully saturated with DO at $6.3 \mathrm{mg} / \mathrm{L}$ at the time of inoculation but dropped to $4.7 \mathrm{mg} / \mathrm{L}$ after 2 days growth (Fig. 6). However, after 2 days of growth anoxic regions of 1.5 $\mathrm{mg} / \mathrm{L}$ were seen developing underneath the larger microcolonies. After HMV treatment to the right chamber the larger colonies were removed and the DO returned immediately to $6 \mathrm{mg} / \mathrm{L}$. However, less oxic regions persisted around the edge of the chamber presumably caused by physiological activity of biofilm which had been removed from the central area of the chamber to the edges. After a further day of incubation there was notable accumulation of biofilm regrowth and microcolonies reappeared in the center and around the edge of the right chamber. The DO was reduced to around 1.0 $\mathrm{mg} / \mathrm{L}$. The second HVM treatment to the right chamber again removed the distinct biofilm microcolonies from the central region and the DO increased to $6 \mathrm{mg} / \mathrm{L}$.

\section{Petri plate system}

Similar to the dual chamber system, the optode substratum was close to $100 \%$ DO saturation at the time of inoculation. There was little change after 1 day but after 2 days the DO at the base of the biofilm had dropped from approximately $6 \mathrm{mg} / \mathrm{L}$ to $0.1 \mathrm{mg} / \mathrm{L}$ (Fig. 7). Unlike the dual chamber system, the DO distribution was fairly homogeneous since there were less large distinct microcolonies. After HVM treatment to the optode on day 6 the DO 


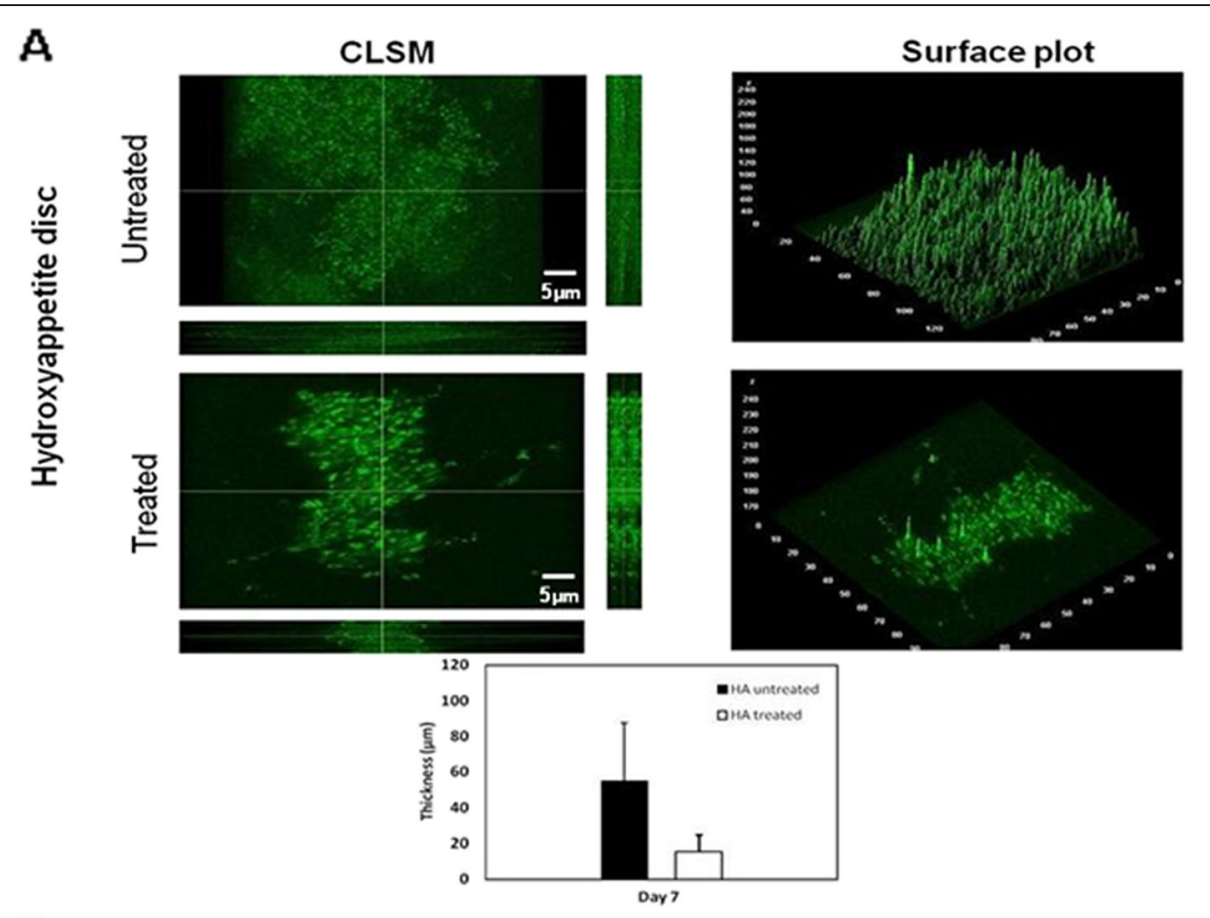

B

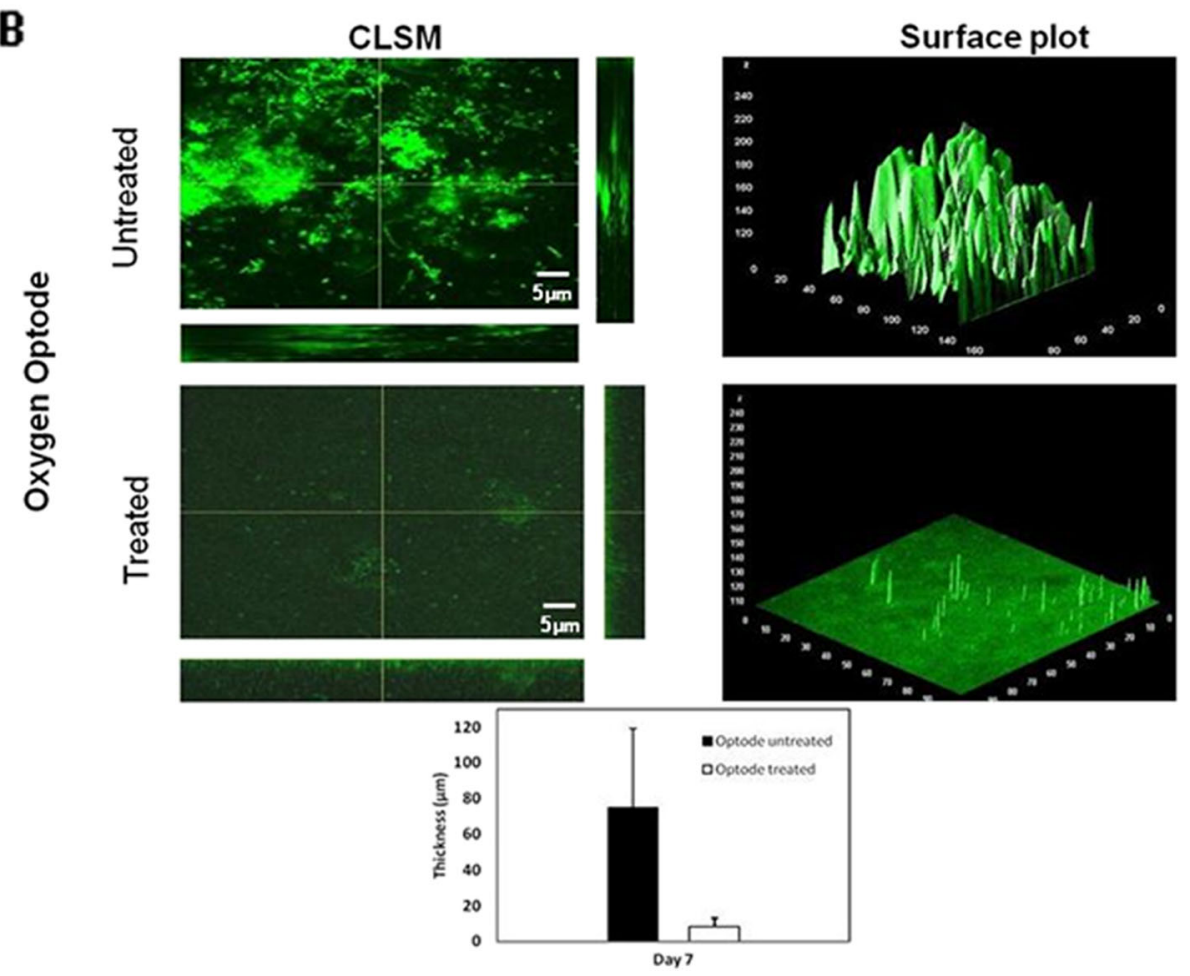

Fig. 5 COMSTAT2 analysis of 7 day old saliva/plaque biofilm grown on the HA discs and an oxygen optode in the Petri plate system. Maximum biofilm thickness quantified with COMSTAT2 on HA discs ( 3 biological replicates each with 3 fields of view in each arm) and (b) and the oxygen optode (one optode with three fields of view in the HMV shot and undistrurbed biofilm areas). Differences in thickness between the HMV shot and undisturbed areas were statistically significant $(P<0.05$ by unpaired Student's t-test)

increased to $1.5 \mathrm{mg} / \mathrm{L}$ in the cleared circular region of $0.57 \mathrm{~cm}^{2}(0.85 \mathrm{~cm}$ diameter) where biofilm was removed. After a further days of incubation biofilm had grown back into the cleared region reducing it to $0.08 \mathrm{~cm}^{2}(0.32 \mathrm{~cm}$ diameter). The $\mathrm{DO}$ in this region had reduced to $1 \mathrm{mg} / \mathrm{L}$ but was still higher than prior to treatment $(0.1 \mathrm{mg} / \mathrm{L})$. After the second HVM treatment the cleared zone increased to $0.40 \mathrm{~cm}^{2}(0.72 \mathrm{~cm}$ diameter $)$ which was less 

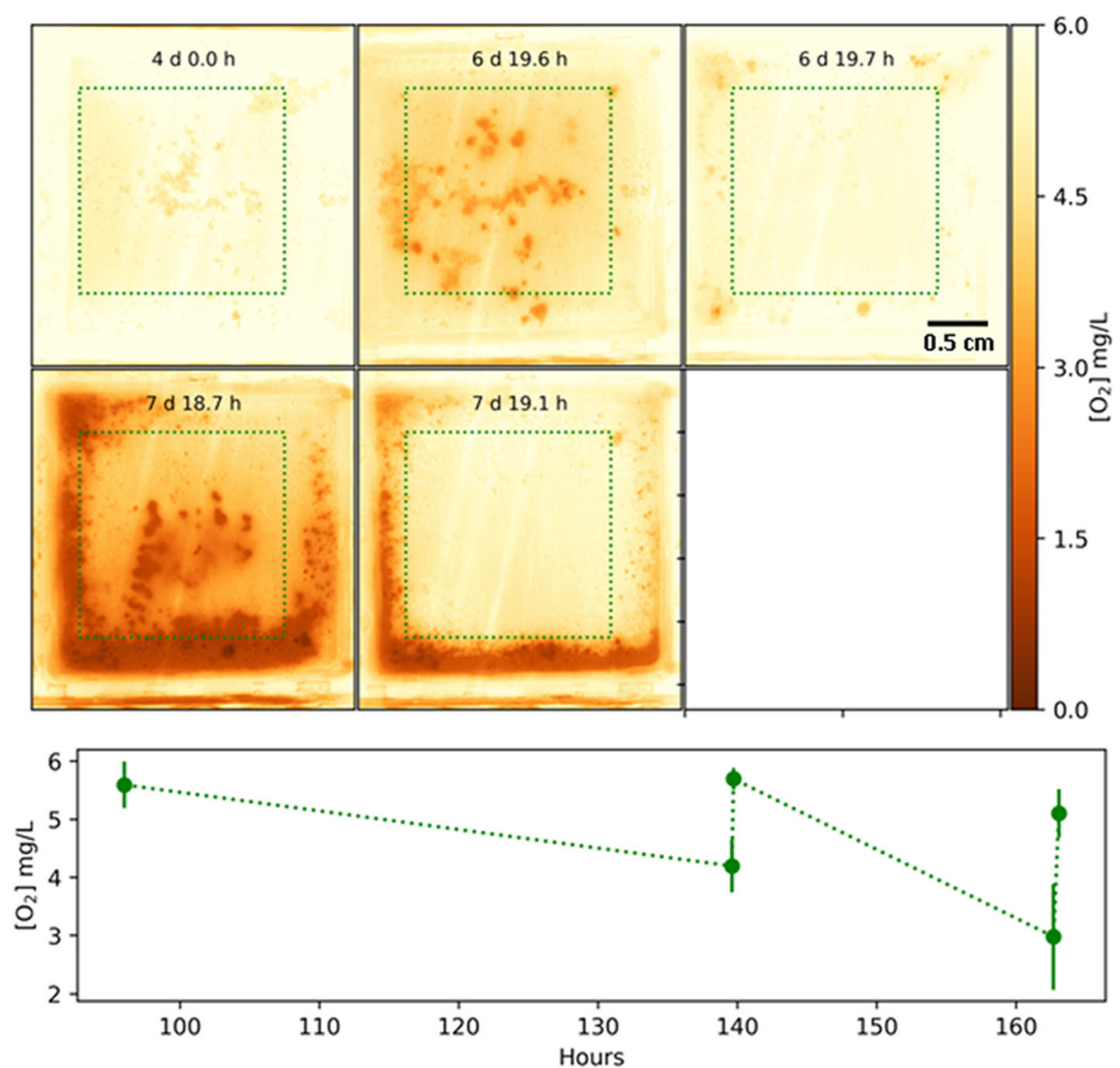

Fig. 6 Dissolved oxygen in the dual chamber before and after HVM treatment. Top panels are a time series showing the DO distribution represented as a false-color image. The graph below shows the DO concentration across the shot area (marked with profile lines in the images) at the various time points. The biofilm was exposed to HVM treatment at 6 days and again at 7 days. The diameter of the area cleared by the HVM was approximately $1 \mathrm{~cm}$

than had been achieved with the original HVM and the DO only increased to $1 \mathrm{mg} / \mathrm{L}$ the second time.

\section{Bacterial community analysis from the optode in the petri} plate system

qPCR showed clear differences in the amount of DNA amplified from the HVM treated area compared to the undisturbed (untreated control) area (Fig. 8a). In the untreated area the total copy number was $2.16 \times 10^{11}$. After HVM treatment the total cell copy number was reduced to $2.62 \times 10^{09}$, an approximate $2 \log$ reduction (Fig. $8 \mathrm{~b}$ ). All of the targeted species showed a reduction ranging from an approximate $1 \log$ reduction for S. gordonii to over a 3 log reduction for Veillonella spp. There was no clear trend indicating whether the anaerobic species were selectively removed relative to the facultative anaerobic Streptococci.

\section{Discussion}

Here we report a method of using planar optodes to measure the influence of mechanical disruption of dental biofilms by HVM on DO concentration at the base of the biofilm. Previously, we have measured DO profiles in ex-situ human dental biofilms with microelectrodes to show that anoxic regions are created near the base of the biofilm and although antimicrobial dentifrices reduce microbial activity in the upper parts of the biofilm the anoxic regions remained active [8]. While DO microelectrodes are extremely useful for measuring respiration rates and the development of anoxic conditions under varying conditions at different depths in biofilms, they do not easily provide a 2D oxygen distribution map of DO concentrations at the base of the biofilm. They are also very fragile and cannot be used during the application of mechanical disruption technologies due to issues with vibration and breakage. Ratiometric dyes have been used to show anoxia at the base of undisturbed dental biofilms [44] but mechanical disruption will wash such dyes out complicating interpretation of the results. Planar optodes have been previously utilized to map oxygen in sediments [45] and heterotrophic biofilms as a function of flow rate [46] but not to our knowledge in dental biofilms undergoing mechanical disruption. 

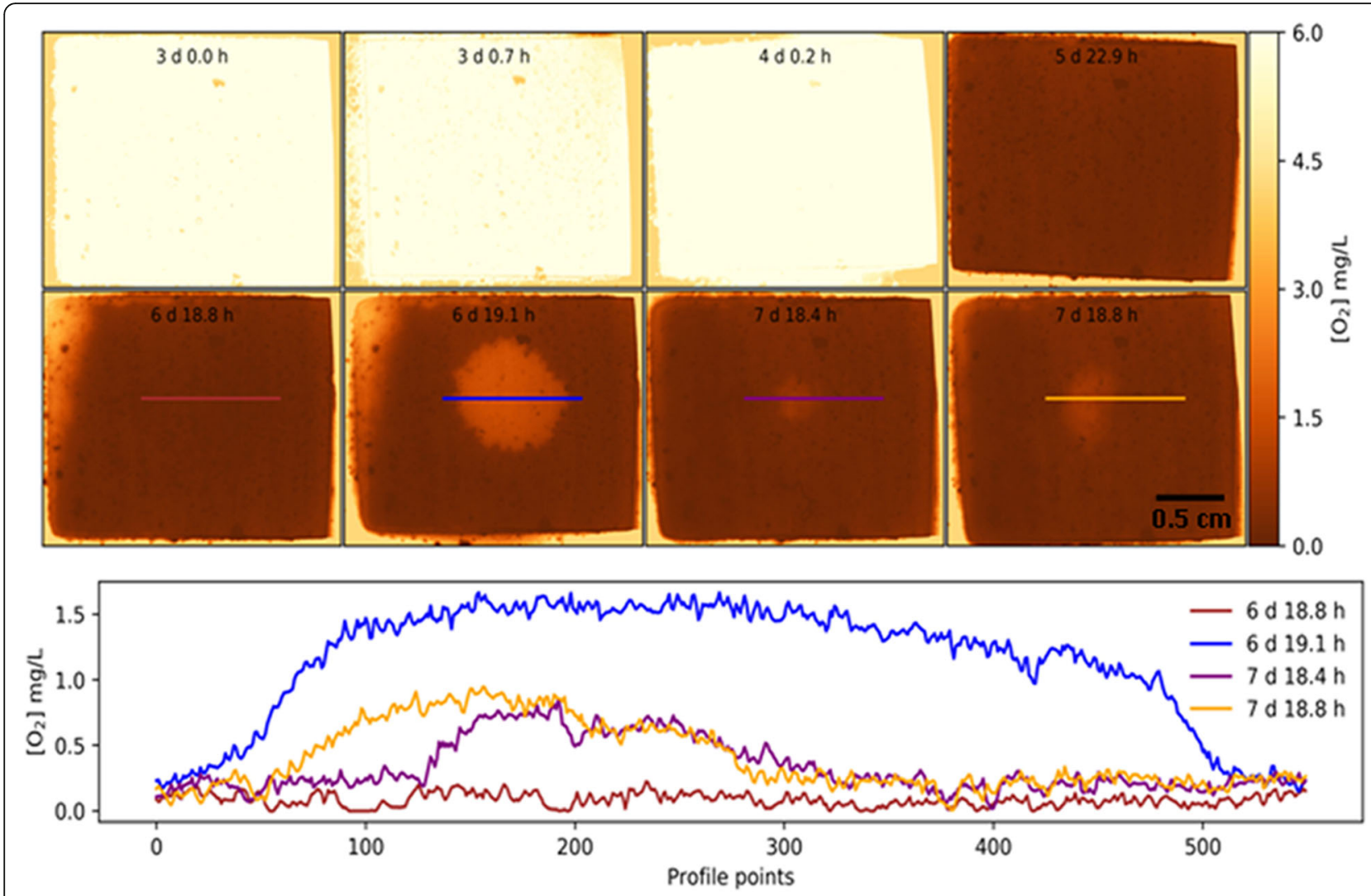

Fig. 7 Dissolved oxygen profile across the HVM treated area in the Petri plate biofilm. Top panels are a time series showing the oxygen distribution represented as a color heat map. The graph below shows the DO concentration across the HVM cleared area at the various time points. The biofilm was exposed to HVM treatment at 6 days and again at 7 days. The diameter of the HVM cleared area was approximately $1 \mathrm{~cm}$

Biofilm developed on the DO optodes had a similar appearance to that on the HA and polystyrene surfaces. PCR showed that the inoculum contained both early colonizers as well as anaerobic periodontal pathogens. The relative increase in anaerobic species over the 4 days of growth on the HA discs demonstrated that these organisms were still viable even though special considerations with respect to maintaining an anoxic environment were not taken during collection or culturing. It is possible that biofilm aggregates in the saliva or detached during brushing were already providing an anoxic niche, which allowed pathogen numbers to increase as the biofilm developed. Obligate anaerobic species have previously been reported in biofilms grown in flow cells with no special provision to impose an anoxic environment on the culture [29] suggesting that these organisms can occupy that anoxic niches which develop naturally through oxygen consumption from facultative species in the biofilm, allowing anaerobes to thrive in vitro as they might in vivo. In the first few days of biofilm formation of the monitored species Veillonella .spp. dominated in the biofilm. In human plaque the streptococci are known to dominate the supragingival plaque $[47,48]$ however, we only monitored two representative streptococci species and so we likely underestimated the relative proportions. The decrease in streptococci and the increase in Fusobacterium spp. is consistent with the succession seen in natural oral populations.

Treating with the HVM device showed significant mechanical disruption of the biofilm in both optode growth systems and larger microcolonies were visibly removed in the treated areas. After treatment the DO concentration was immediately elevated by 2 fold in the dual chamber system and 10 fold in the Petri plate system rendering the biofilm base from anoxic to oxic. A reason for the greater difference in the Petri plate system might be that the smaller dimensions of walls of the dual chamber system retained detached biofilm within the cleared zone, and particularly around the edges, where it would still have been consuming oxygen in the immediate vicinity, influencing the oxygen concentration. The relative abundance of bacteria in the HVM treated and untreated areas of the same biofilm showed the most pronounced changes in Fusobaterium spp. and P. gingivalis, which showed a 6fold reduction and complete removal, respectively. $P$. gingivalis and $F$. nucleatum belong to the group of strictly anaerobic bacteria associated with periodontal diseases [49]. Due to its numerous putative virulence factors and highly 

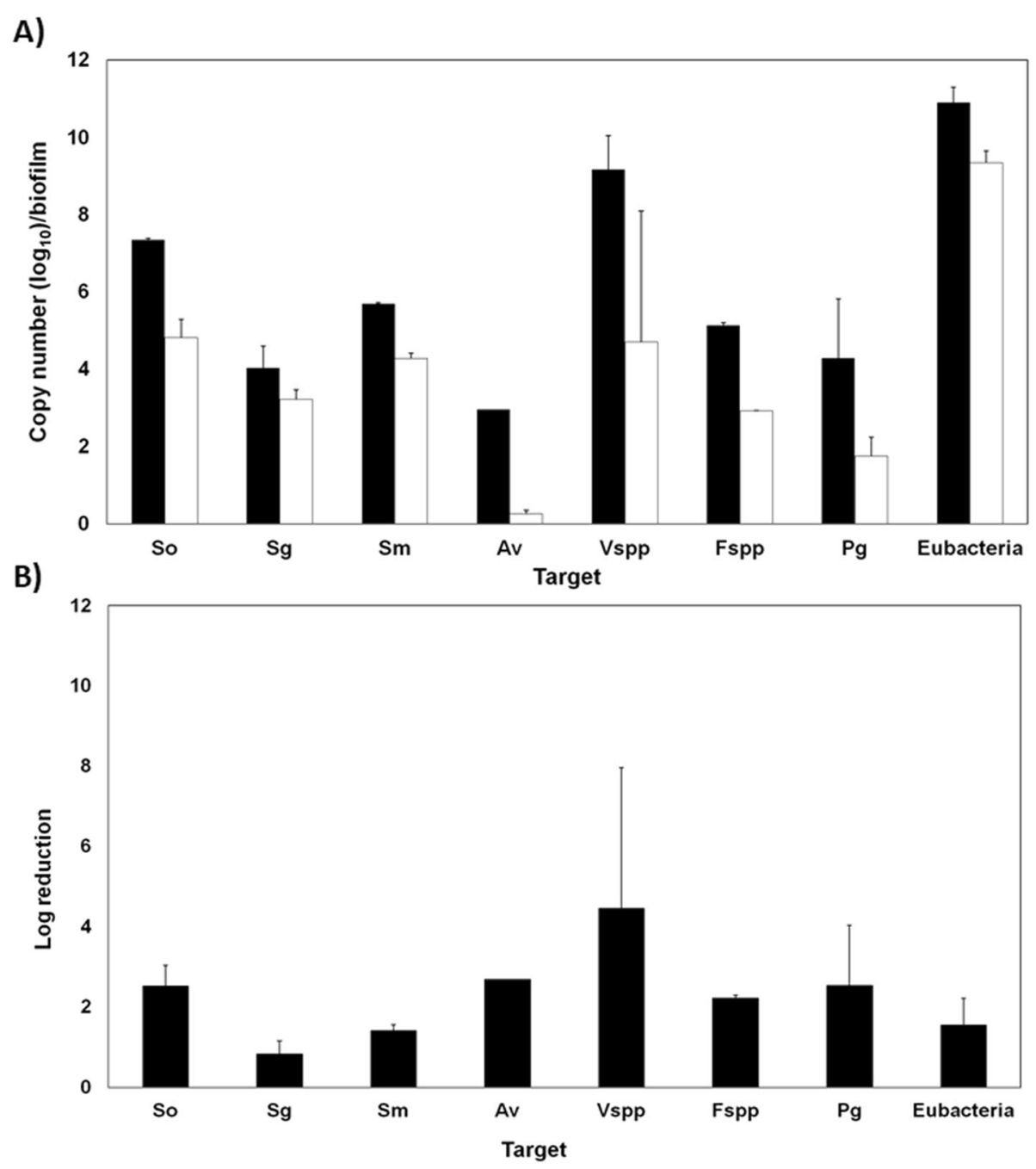

Fig. 8 qPCR relative abundance of target bacterial species grown on the oxygen optodes exposed to the HVM shot area and an equivalent area in an unshot control. a Log ${ }_{(10)}$ copy number per biofilm of undisturbed and HVM treated regions of the biofilm. There was a significant reduction in the target species in the treated areas $(P \leq 0.05)$. Black: Untreated control biofilm, White: HMV treated biofilm. $\mathbf{b}$ Log relative reduction in species abundance after HVM treatment. Data were $\log _{10}$ transformed and presented as geometric mean and 1 SD

inflammatory nature, $P$. gingivalis is considered one of the major periodontopathic bacteria [50] and F. nucleatum is important due to its extensive co-aggregating capacity which bridges commensal and periodontal species in the biofilm [51].

Ideally, mechanical disruption by any interproximal plaque management device would remove all biofilm so that between dental cleanings, the succession is arrested to the early colonizers, however complete removal by mechanical methods is not achievable by any home use device. Recently, we discovered in an $S$. mutans interproximal model that HVM not only removed significant amounts of biofilm from but also caused the remaining biofilm to liquefy allowing more efficient delivery of dentifrices [52]. It is likely that repeated disruption of the biofilm will have an additional therapeutic effect of disrupting anoxic and acidic regions thus shifting the microbes from an anaerobic pathogenic community to a more benign commensal community, thus explaining the observed therapeutic effect [53]. By growing mixed species biofilms, containing obligate anaerobes under an aerobic headspace allowed us to measure how mechanical disruption influences oxygen concentration at the base of the biofilm. However, we point out caution in extrapolating our findings to clinical efficacy. The biofilm plaque model used in this study is was grown in nutrient-rich medium in the absence of real world host factors. Also the device is intended for interproximal delivery. Although jet impingement will create radial shear stresses as the spray radiates outwards from the site of impact inevitably there will be differences between the shear forces generated in our in vitro systems and those 
generated in the IP spaces of the human mouth. Therefore, it is important in future work to determine how the impact of repeated exposure to the microsprays influences microbial communities in longer term studies and how these data compare with those found in human clinical studies.

\section{Conclusions}

In conclusion, we have shown that high velocity microsprays removed a sufficient amount of biofilm to disrupt the anoxic region at the biofilm-surface interface. The management of the biofilm microenvironment through repeated HVM treatment has the potential to select against the highly virulent and immunogenic anaerobic periopathogens.

\section{Supplementary information}

Supplementary information accompanies this paper at https://doi.org/10. 1186/s12903-020-01217-0.

\section{Additional file 1: Figure S1. Presence of representative species and genera in saliva/plaque inoculum. Gel electrophoresis of 165 amplicons from the in vitro biofilms showing presence of the target species and genera. Lane 2-3: two technical replicates of sample, N: Negative control (without DNA), Lane 1: Positive controls with DNA extracted from pure cultures of $P$. gingivalis 33277, S. oralis 10557, F. nucleatum 10953, A. viscosus 43146, V. parvula 17745, S. mutans UA159 and S. gordonii DL1. due to uncertainty of taxonomic identification of $A$. viscosus with respect to identification of this species in human strains we denote this species in quotation marks following Könönen et al. 2015 [38].}

\section{Abbreviations}

DO: Dissolved oxygen (DO); HVM: High velocity microspray; M-BHI: Modified brain heart infusion; qPCR: Quantitative PCR; OD: Optical density; HOMINGS: Human oral microbiome identification using next generation sequencing; TBE: Tris-borate Buffer; UV: Ultraviolet; HA: Hydroxyapatite (HA); CLSM: Confocal laser scanning microscope (CLSM); SO: S. oralis; Sm: S. mutans; Sg: S. gordonii; Av: A. viscosus; Vspp: Veillonella spp.; Vp: V. parvula; Fspp: Fusobacterium spp.; Pg: P. gingivalis; Uni: Universal

\section{Acknowledgements}

We thank all the healthy volunteers in this study who participant in sample collection. Images presented in this report were generated using the instruments and services at the Campus Microscopy and Imaging Facility, The Ohio State University. This facility is supported in part by grant P30 CA016058, National Cancer Institute, Bethesda, MD.

\section{Authors' contributions}

YK, PK, DdB, AC, PS, EMS, MTW, SP designed the experiments; SMB manufactured and provided the optodes, YK, PS, AC, RDPK, SMB analyzed the results; YK and RDPK set up the optode system and performed the experiments; EG conducted the confocal imaging. YK and PS generated the original draft and revisions of the manuscript. All authors read, provided edits and approved the final manuscript

\section{Funding}

This project was funded from Philips Oral Healthcare Project ID: 60056419 and the OSU Infectious Diseases Institute (IDI). EMS, MTW of Philips Oral Healthcare $(\mathrm{POH})$ who funded the project helped design the experiments in consultation with PS.

\section{Availability of data and materials}

All data generated or analyzed during this study are included in this published article and its supplementary information files. Access to raw data can be acquired by connecting to the corresponding author via email.

\section{Ethics approval and consent to participate}

Ohio State University Human Research Protection Program (HRPP), Institutional Review Board (IRB) prepared and approved (2017H0016) to collect saliva and interproximal plaque from healthy consented volunteers and all subjects provided written informed consent to participate.

\section{Consent for publication}

Not applicable.

\section{Competing interests}

The authors declare that they have no competing interests.

\section{Author details}

${ }^{1}$ Department of Microbial Infection and Immunity, Ohio State University, Columbus, USA. ${ }^{2}$ Max Planck Institute for Marine Microbiology, Bremen, Germany. ${ }^{3}$ College of Dentistry, The Ohio State University, Columbus, $\mathrm{OH}$, USA. ${ }^{4}$ Institute of Analytical Chemistry and Food Chemistry Graz University of Technology Stremayrgasse, Graz, Austria. ${ }^{5}$ Philips Oral Healthcare, Bothell, Washington 98021, USA. ${ }^{6}$ Department Orthopaedics, Ohio State University, Columbus, USA. ${ }^{7}$ National Centre for Advanced Tribology (nCATS),

Mechanical Engineering, University of Southampton, Southampton, UK.

Received: 16 August 2019 Accepted: 12 August 2020

Published online: 21 August 2020

\section{References}

1. Silva CB, Mendes MM, Rodrigues BR, Pereira $T L, D B R$, Rodrigues Junior V, VPL F, Geraldo-Martins VR, Nogueira RD. Streptococcus mutans detection in saliva and colostrum samples. Einstein (São Paulo). 2019;17(1):eAO4515.

2. Baker JL, Edlund A. Exploiting the oral microbiome to prevent tooth decay: has evolution already provided the best tools? Front Microbiol. 2018:9:3323.

3. Liu J, Wu C, Huang I-H, Merritt J, Qi F. Differential response of Streptococcus mutans towards friend and foe in mixed-species cultures. Microbiology. 2011;157(Pt 9):2433.

4. Kreth J, Merritt J, Shi W, Qi F. Competition and coexistence between Streptococcus mutans and Streptococcus sanguinis in the dental biofilm. J Bacteriol. 2005:187(21):7193-203.

5. Kolenbrander PE. Multispecies communities: interspecies interactions influence growth on saliva as sole nutritional source. Int J Oral Sci. 2011;3(2):49.

6. Kolenbrander PE, Palmer RJ Jr, Rickard AH, Jakubovics NS, Chalmers NI, Diaz PI. Bacterial interactions and successions during plaque development. Periodontology 2000. 2006:42(1):47-79.

7. Aas JA, Griffen AL, Dardis SR, Lee AM, Olsen I, Dewhirst FE, Leys EJ, Paster $\mathrm{BJ}$. Bacteria of dental caries in primary and permanent teeth in children and young adults. J Clin Microbiol. 2008;46(4):1407-17.

8. von Ohle C, Gieseke A, Nistico L, Decker EM, DeBeer D, Stoodley P. Realtime microsensor measurement of local metabolic activities in ex vivo dental biofilms exposed to sucrose and treated with chlorhexidine. Appl Environ Microbiol. 2010;76(7):2326-34.

9. Chen T, Yu W-H, Izard J, Baranova OV, Lakshmanan A, Dewhirst FE. The human Oral microbiome database: a web accessible resource for investigating oral microbe taxonomic and genomic information. Database. 2010;2010:baq013.

10. Socransky S, Haffajee A, Cugini M, Smith C, Kent R Jr. Microbial complexes in subgingival plaque. J Clin Periodontol. 1998;25(2):134-44.

11. Velsko IM, Yates JAF, Aron F, Hagan RW, Frantz LA, Loe L, Martinez JBR, Chaves E, Gosden C, Larson G. Microbial differences between dental plaque and historic dental calculus are related to oral biofilm maturation stage. Microbiome. 2019:7(1):102.

12. Bourgeois D, Bravo M, Llodra J-C, Inquimbert C, Viennot S, Dussart C, Carrouel F. Calibrated interdental brushing for the prevention of periodontal pathogens infection in young adults-a randomized controlled clinical trial. Sci Rep. 2019;9(1):1-13.

13. Holt SC, Ebersole J, Felton J, Brunsvold M, Kornman KS. Implantation of Bacteroides gingivalis in nonhuman primates initiates progression of periodontitis. Science. 1988:239(4835):55-7.

14. Hajishengallis $\mathrm{G}$, Lamont RJ. Beyond the red complex and into more complexity: the polymicrobial synergy and dysbiosis (PSD) model of periodontal disease etiology. Mol Oral Microbiol. 2012;27(6):409-19.

15. Hajishengallis G, Liang S, Payne MA, Hashim A, Jotwani R, Eskan MA, Mclntosh ML, Alsam A, Kirkwood KL, Lambris JD. Low-abundance biofilm species 
orchestrates inflammatory periodontal disease through the commensal microbiota and complement. Cell Host Microbe. 2011;10(5):497-506.

16. Haffajee A, Cugini M, Tanner A, Pollack R, Smith C, Kent R Jr, Socransky S. Subgingival microbiota in healthy, well-maintained elder and periodontitis subjects. J Clin Periodontol. 1998;25(5):346-53.

17. He J, Huang W, Pan Z, Cui H, Qi G, Zhou X, Chen H. Quantitative analysis of microbiota in saliva, supragingival, and subgingival plaque of Chinese adults with chronic periodontitis. Clin Oral Investig. 2012;16(6):1579-88.

18. De Jager M, Jain V, Schmitt P, DeLaurenti M, Jenkins W, Milleman J, Milleman K, Putt M. Effect of Philips Sonicare AirFloss on interproximal plaque and gingivitis; 2015

19. Mwatha A, Olson M, Souza S, Ward M, Jenkins W, Amini P, Gallob MJ, Fafard BT. Gingival health and plaque regrowth response following a four-week interdental hygiene intervention. J Clin Dent. 2017;28(1):A36-44.

20. Nammi K, Starke E, Ou S, Ward M, Jenkins W, Milleman JL, Milleman K. The effects of use of a powered and a manual home oral hygiene regimen on plaque and gum health in an orthodontic population. J Clin Dentistry. 2019; 30(Spec No A):A1-8.

21. Fabbri S, Li J, Howlin RP, Rmaile A, Gottenbos B, De Jager M, Starke EM Aspiras M, Ward MT, Cogan NG. Fluid-driven interfacial instabilities and turbulence in bacterial biofilms. Environ Microbiol. 2017;19(11):4417-31.

22. Fabbri S, Johnston D, Rmaile A, Gottenbos B, De Jager M, Aspiras M, Starke E, Ward M, Stoodley P. High-velocity microsprays enhance antimicrobial activity in Streptococcus mutans biofilms. J Dent Res. 2016;95(13):1494-500.

23. Glud RN, Santegoeds CM, De Beer D, Kohls O, Ramsing NB. Oxygen dynamics at the base of a biofilm studied with planar optodes. Aquat Microb Ecol. 1998;14(3):223-33.

24. Wang X-d, Wolfbeis OS. Optical methods for sensing and imaging oxygen: materials, spectroscopies and applications. Chem Soc Rev. 2014;43(10):3666-761.

25. Larsen M, Borisov SM, Grunwald B, Klimant I, Glud RN. A simple and inexpensive high resolution color ratiometric planar optode imaging approach: application to oxygen and pH sensing. Limnol Oceanogr Methods. 2011;9(9):348-60.

26. Moßhammer M, Strobl M, Kühl M, Klimant I, Borisov SM, Koren K. Design and application of an optical sensor for simultaneous imaging of $\mathrm{pH}$ and dissolved O2 with low cross-talk. Acs Sensors. 2016;1 (6):681-7.

27. Klimant I, Meyer V, Kühl M. Fiber-optic oxygen microsensors, a new tool in aquatic biology. Limnol Oceanogr. 1995;40(6):1159-65.

28. Vendruscolo F, Rossi MJ, Schmidell W, Ninow JL. Determination of oxygen solubility in liquid media. ISRN Chem Eng. 2012;2012:601458.

29. Nance WC, Dowd SE, Samarian D, Chludzinski J, Delli J, Battista J, Rickard AH. A high-throughput microfluidic dental plaque biofilm system to visualize and quantify the effect of antimicrobials. J Antimicrob Chemother. 2013;68(11):2550-60

30. Takahashl N, Saito K, Schachtele C, Yamada T. Acid tolerance and acidneutralizing activity of Porphyromonas gingivalis, Prevotella intermedia and Fusobacterium nucleatum. Oral Microbiol Immunol. 1997:12(6):323-8.

31. Tang G, Yip H-K, Cutress TW, Samaranayake LP. Artificial mouth model systems and their contribution to caries research: a review. J Dent. 2003; 31(3):161-71.

32. Rmaile A, Carugo D, Capretto L, Wharton J, Thurner P, Aspiras M, Ward M, De Jager M, Stoodley P. An experimental and computational study of the hydrodynamics of high-velocity water microdrops for interproximal tooth cleaning. J Mech Behav Biomed Mater. 2015;46:148-57.

33. Prades L, Fabbri S, Dorado AD, Gamisans X, Stoodley P, Picioreanu C. Computational and Experimental Investigation of Biofilm Disruption Dynamics Induced by High-Velocity Gas Jet Impingement. mBio. 2020;11(1): e02813-9.

34. Park S-N, Lim YK, Kook J-K. Development of quantitative real-time PCR primers for detecting 42 oral bacterial species. Arch Microbiol. 2013;195(7): 473-82.

35. Suzuki N, Yoshida A, Nakano Y. Quantitative analysis of multi-species oral biofilms by TaqMan real-time PCR. Clin Med Res. 2005;3(3):176-85.

36. Àlvarez G, González M, Isabal S, Blanc V, León R. Method to quantify live and dead cells in multi-species oral biofilm by real-time PCR with propidium monoazide. AMB Express. 2013;3(1):1.

37. Chalmers NI, Palmer RJ, Cisar JO, Kolenbrander PE. Characterization of a Streptococcus sp.-Veillonella sp. community micromanipulated from dental plaque. J Bacteriol. 2008;190(24):8145-54.

38. Könönen $E$, Wade WG. Actinomyces and related organisms in human infections. Clin Microbiol Rev. 2015;28(2):419-42.
39. Kirakodu SS, Govindaswami M, Novak MJ, Ebersole JL, Novak KF. Optimizing qPCR for the quantification of periodontal pathogens in a complex plaque biofilm. Open Dent J. 2008;2:49.

40. Yamashita K, Nishiyama T, Nagata E, Ramadhani A, Kawada-Matsuo M, Komatsuzawa H, Oho T. Impact of a 7-day field training on Oral health condition in Japan ground self-defense force personnel. Mil Med. 2017; 182(7):e1869-77.

41. Carrouel F, Viennot S, Santamaria J, Veber P, Bourgeois D. Quantitative molecular detection of 19 major pathogens in the interdental biofilm of periodontally healthy young adults. Front Microbiol. 2016;7:840.

42. Kim M, Jeon J, Kim J. Streptococcus mutans extracellular DNA levels depend on the number of bacteria in a biofilm. Sci Rep. 2018;8(1):13313.

43. Hong W, Pang B, West-Barnette S, Swords WE. Phosphorylcholine expression by nontypeable Haemophilus influenzae correlates with maturation of biofilm communities in vitro and in vivo. J Bacteriol. 2007; 189(22):8300-7.

44. Gerritsen $\mathrm{HC}$, de Grauw CJ. Fluorescence lifetime imaging of oxygen in dental biofilm. In: Laser Microscopy: 2000: International Society for Optics and Photonics; 2000. p. 70-8

45. Polerecky L, Franke U, Werner U, Grunwald B, de Beer D. High spatial resolution measurement of oxygen consumption rates in permeable sediments. Limnol Oceanogr Methods. 2005;3(2):75-85.

46. Staal M, Borisov S, Rickelt LF, Klimant I, Kühl M. Ultrabright planar optodes for luminescence life-time based microscopic imaging of $\mathrm{O} 2$ dynamics in biofilms. J Microbiol Methods. 2011;85(1):67-74.

47. Palmer RJ, Diaz PI, Kolenbrander PE. Rapid succession within the Veillonella population of a developing human oral biofilm in situ. J Bacteriol. 2006; 188(11):4117-24.

48. Periasamy S, Kolenbrander PE. Central role of the early colonizer Veillonella $\mathrm{sp}$. in establishing multispecies biofilm communities with initial, middle, and late colonizers of enamel. J Bacteriol. 2010;192(12):2965-72.

49. Ximénez-Fyvie LA, Haffajee AD, Socransky SS. Comparison of the microbiota of supra-and subgingival plaque in health and periodontitis. J Clin Periodontol. 2000;27(9):648-57.

50. Lamont RJ, Jenkinson HF. Life below the gum line: pathogenic mechanisms ofPorphyromonas gingivalis. Microbiol Mol Biol Rev. 1998;62(4):1244-63.

51. Kolenbrander P, Andersen R, Moore L. Coaggregation of Fusobacterium nucleatum, Selenomonas flueggei, Selenomonas infelix, Selenomonas noxia, and Selenomonas sputigena with strains from 11 genera of oral bacteria. Infect Immun. 1989;57(10):3194-203.

52. Fabbri S, Johnston D, Rmaile A, Gottenbos B, De Jager M, Aspiras M, Starke E, Ward M, Stoodley P. Streptococcus mutans biofilm transient viscoelastic fluid behaviour during high-velocity microsprays. J Mech Behav Biomed Mater. 2016:59:197-206.

53. Bruce JD. Effect of philips sonicare airfloss on plaque index, gingival index, and bleeding index in patients with fixed orthodontic appliances. ProQuest Dissertations Publishing, Saint Louis University; 2013:1552041.

\section{Publisher's Note}

Springer Nature remains neutral with regard to jurisdictional claims in published maps and institutional affiliations.

Ready to submit your research? Choose BMC and benefit from:

- fast, convenient online submission

- thorough peer review by experienced researchers in your field

- rapid publication on acceptance

- support for research data, including large and complex data types

- gold Open Access which fosters wider collaboration and increased citations

- maximum visibility for your research: over $100 \mathrm{M}$ website views per year

At $\mathrm{BMC}$, research is always in progress.

Learn more biomedcentral.com/submissions 